\title{
Innovative and safe supply of fuels for reactors
}

\author{
Stéphane Valance ${ }^{1, *}$, Bruno Baumeister ${ }^{2}$, Winfried Petry ${ }^{2}$, and Jan Höglund ${ }^{3}$ \\ ${ }^{1}$ CEA, DEN, DEC, Cadarache, 13108 Saint-Paul-lez-Durance, France \\ ${ }^{2}$ Forschungs-Neutronenquelle Heinz Maier-Leibnitz (FRM II), Technische Universität München, Lichtenbergstrass, 1, \\ 85747 Garching, Germany \\ ${ }^{3}$ Westinghouse Electric Sweden AB., 72163 Västerås, Sweden
}

Received: 12 March 2019 / Accepted: 4 June 2019

\begin{abstract}
Within the Euratom research and training program 2014-2018, three projects aiming at securing the fuel supply for European power and research reactors have been funded. Those three projects address the potential weaknesses - supplier diversity, provision of enriched fissile material - associated with the furbishing of nuclear fuels. First, the ESSANUF project, now terminated, resulted in the design and licensing of a fuel element for VVER-440 nuclear power plant manufactured by Westinghouse. The HERACLES-CP project aimed at preparing the conversion of high performance research reactor to low enriched uranium fuels by exploring fuels based on uranium-molybdenium. Finally, the LEU-FOREvER pursues the work initiated in HERACLES-CP, completing it by an exploration of the high-density silicide fuels, and including the diversification of fuel supplier for soviet designed European medium power research reactor. This paper describes the projects goals, structure and their achievements.
\end{abstract}

\section{Introduction}

At the core of reactor operation, nuclear fuel is a consumable which necessitates a secure supply chain. In EU, that entails a diversity of suppliers with licensed fuel design and the availability of enriched uranium. Particularly, reactors with an original soviet design present a weakness in their supply chain as they depend on a single manufacturer. In Europe, this is the case for VVER-440 power plants and medium power research reactors. High Power Research Reactors (HPRRs), with more standardized fuel designs, are, on their side, vulnerable to the supply of high enriched uranium necessary to ensure their performance.

Diversification of fuel element supply requires the adaptation of non-historic fuel manufacturers to the specificities of the reactor. The first step of this diversification is thus reverse engineering to tackle all the technical functions of the element for any type of operating conditions. Then, a design has to be set-up which fulfils the identified functions and is adapted to the producing means of the new manufacturer. Finally, the new fuel element should be licensed within one or several countries. This last step might involve an irradiation depending on the reactor specific needs.

\footnotetext{
* e-mail: stephane.valance@cea.fr
}

With respect to enriched uranium supply, global efforts are made to minimize the use of highly enriched uranium in research reactors. In the EU, this conversion from highly to lower enriched uranium has already begun and is currently ongoing towards the qualification phase. This concerns both medium and high power research reactors. To reach this goal, the adopted path is the development of fuels core which presents a higher fissile uranium content without overcoming the $19.75 \%$ nonproliferant enrichment limit. Three ways have been identified to reach this goal: high density dispersed silicide fuels, dispersed uranium-molybdenum fuels and monolithic uranium-molybdenum fuels.

In this paper, a presentation of each of the projects is done. Then the achievements for innovative and safe supply of the fuel permitted thanks to the EU funding are presented. Finally, a global picture of the challenges solved and remaining questions is drawn.

\section{$2 \mathrm{H} 2020$ projects enabling innovative and safe supply of fuels}

\subsection{ESSANUF}

Several countries in Eastern Europe rely heavily on electricity generated from Russian-design VVER-440 pressurized water reactors. Currently, the Russian company TVEL is the sole supplier of nuclear fuel to these facilities. 
The EU-funded ESSANUF project was launched with the goal to design a state-of-the-art fuel for VVER-440 reactors in full compliance with nuclear safety standards.

ESSANUF (European Supply of Safe NUclear Fuel) [1] is the Euratom funded project from 2016 to 2017 with the overall objective to create greater security of fuel supply to countries operating VVER-440 nuclear power plants in Czech Republic, Finland, Hungary, Slovakia and Ukraine. The project enables the re-entry of Westinghouse as nuclear fuel supplier to VVER-440 offering diversification and greater security of fuel supply.

The project is led by Westinghouse Sweden and includes eight consortium partners: VUJE, ÚJV Řě̌ (NRI), Lappeenranta University of Technology (LUT), National Nuclear Laboratory (NNL), NucleoCon, National Science Center Kharkov Institute of Physics and Technology (NSC KIPT), Institute for Transuranium Elements of the Joint Research Centre of the European Commission (JRC-ITU) and Enusa Industrias Avanzadas (ENUSA). The consortium covers by their geographical distribution the targeted countries operating VVER-440 nuclear power plants.

Within the project, an improved VVER-440 fuel design has been developed and the manufacturing capabilities assessed [2]. Furthermore, the project contributed to the generation of a generic licensing methodology for VVER440 fuel and the set-up of tools enabling to perform the required analyses and investigations for licensing $[3,4]$.

The ESSANUF team selected the most suitable materials for all the fuel assembly components and identified necessary modifications to the earlier supplied VVER-440 assembly design to fulfil utility needs and regulatory requirements of each country. A development programme was established to test and verify the modified design and its manufacturability was assessed to identify any changes needed to the manufacturing processes and equipment.

Thereafter, the project partners developed and validated methods and methodologies necessary to qualify operation of the modified fuel design in the participating countries. In particular, the models to simulate the fuel rod thermomechanical behaviour, corrosion and hydrogen uptake were improved enabling significant advances in the design of the fuel rods.

In addition to the VVER-440 nuclear fuel design, the ESSANUF project partners established the methods and methodologies required to qualify the fuel design for operation in Finland, Hungary, Slovakia, Czech Republic and Ukraine.

Also, significant progress was made to verify and validate the methods and methodologies to simulate the neutronic and thermal hydraulic behaviour of the fuel design. Researchers developed a nuclear criticality safety methodology for the EU and Ukraine based on International Atomic Energy Agency guidelines and regulations, taking into account national requirements.

\subsection{HERACLES-CP}

HERACLES-CP [5], a Euratom project, funded from 2015 to 2019 , is a central pillar of the overall fuel development program of the HERACLES, a pan-European group which gathers the high power research reactor operators ILL, SCK-CEN, CEA and TUM as well as the fuel manufacturer Framatome-CERCA. "CP" stands for "Comprehension Phase".

The general objective of this project is the provision of the technical and scientific foundations for the successful qualification of UMo, a new research reactor fuel based on uranium-molybdenum (UMo) alloys, which is developed in the framework of the joint international efforts to reduce the risk of proliferation by minimising the use of highly enriched uranium. UMo based nuclear fuels, monolithic and dispersed, are promising candidates to carry out the conversion of HPRRs (High Performance Research Reactors). In such a fuel system, the addition of molybdenum to uranium stabilises the body-centred cubic crystal structure of the high-temperature $\gamma$-phase of uranium under irradiation. Hence, the transition to the low-temperature orthorhombic $\alpha$-phase with its strongly anisotropic thermal expansion is prevented with an addition of 7 to $10 \mathrm{wt} . \%$ Mo. This stoichiometry has been proven to be the best compromise between achievable uranium density and stabilisation of the phase behaviour.

Despite being the most promising candidate, significant obstacles were encountered on the way to qualification of UMo fuels in the challenging environment of the HPRRs, particularly with respect to density of dispersion fuel, power and burnup. The very first in-pile tests (IRIS2, FUTURE, IRIS3 $0.3 \% \mathrm{Si}$ ) of nuclear fuels with a UMo/Al composition showed an unacceptable swelling under irradiation, in some cases even leading to plate breakaway, even though these tests were only performed with limited surface power $\left(\leq 350 \mathrm{~W} . \mathrm{cm}^{-2}\right)[6-8]$. The failure has been traced back to a UMo/Al Inter-Diffusion Layer (IDL) growing during in-pile irradiation at UMo-Al interfaces and to its unsatisfactory properties under irradiation [9].

The developments performed worldwide over the last fifteen years have successfully limited the IDL growth [10]. The beneficial effect of Si additions to the dispersion UMo fuel, and more recently the coating of UMo particles with a diffusion barrier can be observed in the gradual, controlled swelling up to higher burnups. A dispersion of UMo particles coated by Physical Vapour Deposition (PVD) with a $1 \mu \mathrm{m}$ thick $\mathrm{ZrN}$ layer, dispersed in an $\mathrm{Al}$ matrix, is currently the baseline solution for the conversion of most European HPRRs.

The main objectives of the program are (see Fig. 1):

- for dispersed fuel:

- to fill the knowledge gaps identified by performing the necessary experiments and measurements,

- to conclude on the most promising fuel design based on the results of these,

- to develop the necessary production techniques and,

- to prepare a SEMPER FIDELIS irradiation test to verify the theory and to fill the gaps that require new irradiation data; 


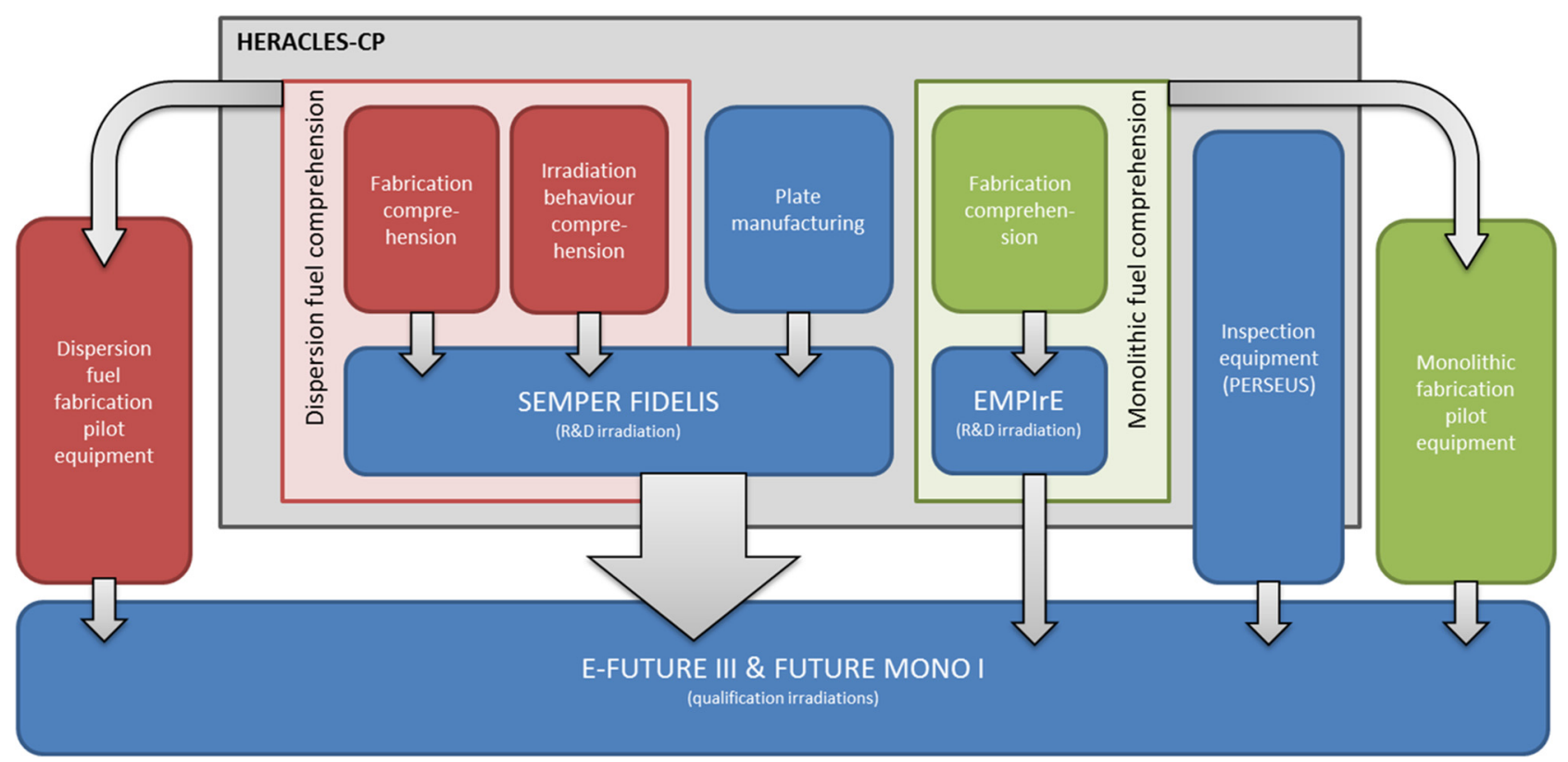

Fig. 1. Flow chart of the HERACLES-CP project.

- for monolithic fuel:

- to develop the technology and knowledge necessary for fabrication and,

- to prepare test samples for the EMPIrE irradiation test;

- for both:

- to develop the technology necessary for the irradiation test as well as the tools for analysis,

- to launch and conduct the irradiation test and finally,

- to perform the Post-Irradiation Examinations (PIE) of SEMPER FIDELIS.

Through the first results of this project, it is already asserted that the UMo fuel is a thinkable way for the replacement of high enriched uranium in HPRRs.

\subsection{LEU-FOREvER}

Following the still on-going HERACLES-CP Euratom funded project, a second Euratom funded project, LEUFOREvER [11,12], has been launched for the period 20172021 with the following identified goals to secure nuclear fuel supply for European research reactors:

- the ongoing conversion of High Performance Research Reactors (HPRRs) from high to low enriched nuclear fuels (LEU), and;

- the difficult market situation for obtaining fuel elements for Medium Power Research Reactors (MPRRs) with an original Soviet design.

A multi-disciplinary consortium - composed of fuel and core designers, nuclear research centers operating research reactors and fuel manufacturers - has been set up to tackle both issues in the framework of the H2020 European Project LEU-FOREvER (2017-2021). Key issues and operative solutions for this topic are underlined in the schematic drawing of Figure 2. This project is carried-out

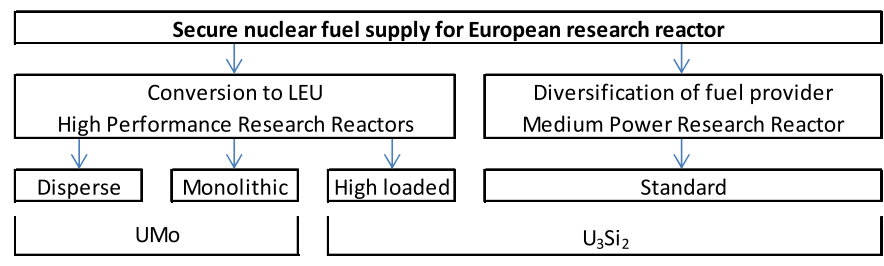

Fig. 2. Key issues and related nuclear fuel development to secure fuel supply for European research reactors.

together by CEA, CVR, Framatome, ILL, NCBJ, SCK $\bullet C E N$, TechnicAtome and TUM. These actors are supplemented by an End-User Group (EUG), an advisory body consisting of representatives from potential end-users of the Project results.

As presented before, the HERACLES group has been developing UMo based solutions, both dispersed and monolithic. Within LEU-FOREvER, optimisation of the manufacturing process up to the construction of pilot equipment, modelling of the in-pile behaviour and post-irradiation examinations of European fuels irradiated in the EMPIrE test at the Advanced Test Reactor (ATR) of the Idaho National Lab (INL) are addressed.

For the dispersed uranium-molybdenum fuel case, the key tasks of the comprehension phase are undoubtedly the tests carried-out in the SEMPER FIDELIS irradiation facility (BR2, Mol-Belgium) and in its sister experiment EMPIrE (ATR, Idaho-USA). These tests, carried out in the framework of the HERACLES group, are aimed at filling the data gaps in the understanding of UMo fuel irradiation behavior and assessing a number of fabrication options for the dispersion UMo fuel. Identified additional knowledge and comprehension gaps will now be addressed in the LEU-FOREvER project. 
Regarding the monolithic UMo fuel type, the developments and assessments performed in the HERACLES-CP project have made it possible to successfully demonstrate that the fabrication of monolithic UMo plates with the appropriate quality is entirely possible with the processes developed in Europe.

As backup strategy to UMo based fuels, high loaded $\mathrm{U}_{3} \mathrm{Si}_{2}$ is considered as a viable solution for the conversion of HPRRs. Within LEU-FOREvER, design and manufacturing of such fuel plates will be optimised and tested in an irradiation experiment under representative high power and burnup conditions.

Lowering enrichment at constant ${ }^{235} \mathrm{U}$ content implies a significant raise of the uranium surface density of the plate. A correlate of this uranium density increase is an increased parasitic absorption due to the higher amount of ${ }^{238} \mathrm{U}$ in the core. This absorption needs to be overcome in order to maintain cycle length and neutron flux. Within a given dispersion fuel system, two options are available to increase the fissile phase content:

- increase the volume fraction of fissile compound in the meat for a dispersion fuel;

- modify the geometry of the fuel assembly and/or fuel plates to accommodate more fuel meat volume, e.g. using thicker plates, larger plates or more plates per assembly.

In an optimized geometry, it would then be possible to increase the quantity of fissile material in the fuel assembly while maintaining the volume fraction of fuel at an acceptable level. One of these options or a combination of both is necessary to create a viable fallback option.

Within the LEU-FOREvER project, manufacturing developments and an irradiation for this high loaded $\mathrm{U}_{3} \mathrm{Si}_{2}$ are planned. The manufacturing developments will permit to ascertain the manufacturability of such geometry modified fuels, and to set the boundary for the use of high loaded $\mathrm{U}_{3} \mathrm{Si}_{2}$ fuels. The High Performance research Reactors Optimized Silicide Irradiation Test (HiPROSIT) experiment will then evaluate the behaviour under irradiation of such modified fuels.

MPRRs (Medium Power Research Reactors) with an original Soviet design currently have only one fuel provider. An alternative to the fuel currently employed will be developed in LEU-FOREvER. Due to some differences between the manufacturing design, the detailed shape and characteristics of the new fuel assemblies, compliant with all the interfaces of the fuel assembly (geometry, performances, safety), will be different. The design of such a fuel therefore implies an in-depth analysis of the reactor and core from neutronics, thermo-hydraulics and overall design point of view. In addition to these technical aspects, special care shall be taken to develop a solution which is above all economically efficient. Thanks to the choice of a proven technology for the fuel element, the potential complementary qualification will only be at fuel assembly level.

For the design of a new fuel assembly, the LVR-15 research reactor will be the most detailed case study. Nevertheless, a first assessment of the BRR core, with a very different current fuel assembly will also be carrying out.
Currently, the reactor uses Russian IRT-4M sandwichtype fuel assemblies mainly composed of concentric square tubes [13], manufactured by NZCHK in Novosibirsk. The meat is composed of a dispersion of $\mathrm{UO}_{2}$ and aluminium powders. The assemblies have the form of six or eight concentric square tubes. The development of a fuel alternative for MPRRs by the LEU-FOREvER project will bring several enhancements for the operators of these reactors:

- much larger ease of use, on a routine basis, of European origin fuel in reactors of Soviet origin;

- ease transition from historical fuel to new fuel, with respect to both technical and regulatory aspects;

- potential improvement of life cycle cost coupled with extended operating cycles.

As most HPRRs will also have to operate with a mixed core configuration during conversion and both HPRRs and MPRR are considering or even already using $\mathrm{U}_{3} \mathrm{Si}_{2} / \mathrm{Al}$ fuel plates, strong synergies are found between the two subprojects.

A fuel element design usable for MPRR has been proposed and is now being manufactured for testing. For HPRR a first batch of high density silicide fuel plates has been manufactured with depleted uranium. The UMo fuel solution is preparing the arrival of samples from the EMPIrE and SEMPER-FIDELIS test irradiations.

\section{Achievements}

ESSANUF generated new knowledge, identifying improvements in the fields of mechanical design, thermo-mechanical fuel rod design, and safety analysis for VVER fuel. This helped to fulfil Europe's need for advanced and reliable nuclear fuel, thereby safeguarding the EU's energy supply by speeding up the diversification of the fuel supply for VVER-440 reactors in the EU and Ukraine.

Furthermore, the project enhanced the communication and relationship between the utilities and regulators of the different countries by encouraging open discussions and the exchange of information between the different parties. The initiative was an important step toward the diversification of the nuclear fuel market in the countries involved, providing long-term benefits to the utilities, industries and citizens that rely on secure electricity supply.

During the project, several workshop were organised to raise interest and share knowledge among the participants and with other bodies, such as potential users or regulations authorities. The project was presented during a meeting of the Expert Group on Multi-Physics Experimental Data Benchmark and Validation of the OECD/NEA. Last but not least, the results were presented during the Finnish Fuel Days in August 2017.

The governing objective of HERACLES-CP is to lay the technical and scientific foundations for the successful qualification of UMo fuel. In this regard, the following progress has already been made.

Within HERACLES-CP, the SEMPER FIDELIS irradiation experiment has been defined and carried out [14]. The first non-destructive examinations show that the 
results are promising at least for one plate. Together with EMPIrE, the experiment will close most of the remaining knowledge gaps. Ion experiments showed no accelerated growth of the interdiffusion layer between $\mathrm{UMo}$ and $\mathrm{Al}$ in the first days of an irradiation.

For the design of the SEMPER FIDELIS irradiation matrix, dozens of experts from the EU and the US have (re-)measured, collected and evaluated data from more than one dozen prior irradiation experiments to ensure that SEMPER FIDELIS will deliver the maximum relevant information for the further development of UMo.

The technique of UMo powder atomization is now understood to an extent that enables the consortium to build the next stage of manufacturing equipment on the pilot level. The construction of the pilot induction furnace has already begun.

Monolithic UMo foils can now be coated with PVD and turned into plates with a very high yield. The technology for this is fully available in Europe.

The HERACLES-CP has been presented at its beginning during an event held at the Bavarian representation in Brussels [15]. The results and findings have been shared and discussed outside the group both in open literature [15-18] and in meetings with US counter sides which are also involved in an intensive conversion program.

In the LEU-FOREvER project, both the actions targeting European HPRR and MPRR have been on track with the laid out plans.

For high density silicide fuels, the test matrix, finite element computations, and depleted uranium fabrications have been done. On the uranium-molybdenum fuels side, the research reactor fuel simulation finite element code MAIA is being updated with latest open literature models for the simulation of the SEMPER FIDELIS experiment. With respect to monolithic uranium-molybdenum fuels, test for the realisation of graded geometries, on surrogate materials have been carried, a fresh sample of monolithic fuel has been received at CEA Cadarache for microscopic examinations, and the retrieval of irradiated samples from the EMPIrE test irradiation has been secured.

The samples issued from the EMPIrE irradiation will be examined in CEA and SCK.CEN. The HiPROSIT irradiation will give key findings on the sustainability of the high-density silicide solution, particularly precising the manufacture possibilities and setting the basis for the effective qualification of fuel for reactors.

To carry the design of a replacement element for the LVR-15 reactor, a multidisciplinary team involving representatives of all involved entities:

- reactor operators, i.e. CVR;

- fuel designers, to optimise both fuel "meat" and fuel "assemblies" i.e. TechnicAtome and Framatome;

- research reactor designers with all the relevant core design experience and calculation codes i.e. Technic Atome.

A preliminary dimensioning has already been developed for a LVR-15 fuel alternative based on assemblies with a European design, i.e. with parallel flat plates and $\mathrm{U}_{3} \mathrm{Si}_{2} / \mathrm{Al}$ meat. Significant manufacturing and operating experience already exists for this kind of fuel assembly in Europe, as the OSIRIS material testing reactor has been fuelled with assemblies of the same geometry and almost the same fuel composition.

Indeed, preliminary drawings have been made for both standard and control fuel elements, making it possible to verify the feasibility of moving from one type to the other. Even if it is still possible to optimize the ${ }^{235} \mathrm{U}$ density, moderator volume, plate shapes, etc. Furthermore, it will be verified that the envisaged $\mathrm{U}_{3} \mathrm{Si}_{2} / \mathrm{Al}$ fuel plate usage in LVR-15 is covered by NUREG 1313 [19] regarding the fuel operational parameters. This will make the qualification phase considerably shorter and cheaper.

By implementing an innovative methodology for fuel assembly design such as the design-to-cost methodology and by involving all relevant parties from designer to manufacturer and to reactor operator, LEU-FOREvER aims to design and produce an economically attractive alternative fuel assembly based on proven European technology, produced by a European manufacturer.

The design of a new element suitable for every European medium power research reactor has given rise to three workshops with the objective to share knowledge on operation and functions of original elements. The organization of a summer school on the research reactor fuels issues is on-going, with a summer school foreseen to take place in October 2020 in Belgium. Several communications on technical achievement have already been done [20-23].

In the coming years, the designed fuel element will be tested for the thermo-hydraulic characteristics and for qualification in the LVR-15 reactor.

\section{Conclusions}

Although different in their targeted scope, all the three Euratom funded project presented in this paper have the goal to secure the supply chain of nuclear fuels, being for nuclear power plant or research reactors. Through their achievement (ESSANUF) or their current findings (HERACLES-CP, LEU-FOREvER), they pave the way for a greater security of supply for nuclear fuel in Europe. The output of these projects will benefit the entire society by ensuring the production of electricity, medical isotopes and cutting edge science.

The ESSANUF project leaded to a renewed, up-todate replacement design for VVER-440 fuel element. Is also fostered collaboration between user and regulatory authorities in the countries using this type of reactor.

The HERACLES-CP project has been the key in understanding innovative fuel systems for high performance research reactors, therefore permitting a selection of the most promising solution to alleviate technological locks.

Finally, the on-going LEU-FOREvER project is both pursuing the goal of converting European high performance reactors and securing the fuel element supply of 
European medium performance research reactors. First results are promising and should, in a coming future, result in the stronger supply chain of research reactor fuels.

At the end of these three projects, EU will have effectively secured the supply chain of fuel elements, resulting in untroubled low carbon emissions for electricity supply, secured supply of medical-radio-isotopes and availability of high performance research instruments.

The ESSANUF project has received funding from the Euratom research and training programme 2014-2018 under grant agreement No. 671546. The HERACLES-CP project has received funding from the Euratom research and training programme 2014-2018 under grant agreement No.661935. The LEUFOREvER project has received funding from the Euratom research and training programme 2016-2017 under grant agreement No. 754378.

\section{References}

1. ESSANUF, ESSANUF homepage, [Online] Available from http://www.essanuf.eu

2. J. Höglund, S. Kristensson, in ESSANUF-European Supply of SAfe NUclear Fuel, 12 International conference on WWER fuel performance, modelling and experimental support, Bulgaria, 2017

3. C. Gyori, P. Blair, M. Jonson, G. Robertson, P. van Uffelen, A. Schubert, B. Hatala, R. Meca, in International Conference Nuclear Energy for New Europe (NENE), Bled, Slovenia, 2017

4. T. Strömgren, Y. Le Moigne, Prediction of critical heat flux in fuel bundles using CFD, in 12 International conference on WWER fuel performance, modelling and experimental support, Bulgaria, 2017

5. HERACLES-CP, HERACLES-CP homepage, [Online] Available from https://heracles-consortium.eu/cp.php

6. S. Dubois, J. Noirot, J. Gatt, M. Ripert, P. Lemoine, P. Boulcourt, in Proceedings of the 11th International Meeting on Research Reactor Fuel Management (RRFM), Lyon, France, 2007

7. F. Huet, J. Noirot, V. Marelle, S. Dubois, P. Boulcourt, P. Sacristan, S. Naury, P. Lemoine, in 9th International Meeting on Research Reactor Fuel Management (RRFM), Budapest, Hungary, 2005

8. A. Leenaers, S. Van den Berghe, E. Koonen, C. Jarousse, F. Huet, M. Trotabas, M. Boyard, S. Guillot, L. Sannen, M. Verwerft, Post-irradiation examination of uranium-7 wt\% molybdenum atomized dispersion fuel, J. Nucl. Mater. 335, 39 (2004)
9. D. Burkes, T. Huber, A. Casella, A model to predict thermal conductivity of irradiated U-Mo dispersion fuel, J. Nucl. Mater. 473, 309 (2016)

10. S. Van den Berghe, P. Lemoine, Review of 15 years of highdensity low-enriched UMo dispersion fuel development for research reactors in Europe, Nucl. Eng. Technol. 46, 125 (2014)

11. LEU-FOREvER, LEU-FOREvER homepage, [Online] Available from https://heracles-consortium.eu/forever.php

12. S. Valance, H. Palancher, F. Huet, B. Stepnik, H. Breitkreuz, S. Van den Berghe, M. Hrerhor, J. Gajewski, in International Meeting on Research Reactor Fuel Management (RRFM), München, Germany, 2018

13. J. Matos, in International Meeting on Reduced Enrichment for Research and Test Reactors (RERTR), Chicago, USA, 2003

14. A. Leenaers, J. Van Eyken, S. Van den Berghe, in International Meeting on Research Reactor Fuel Management (RRFM), Swemieh, Jordan, 2019

15. H. Breitkreuz, J. Hingerl, A. Heldmann, C. Steyer, T. Zweifel, R. Jungwirth, J. Shi, W. Petry, in International Meeting on Reduced Enrichment for Research and Test Reactors (RERTR), Antwerp, Belgium, 2016

16. B. Stepnik, M. Grasse, C. Jarousse, H. Breitkreutz, C. Steyer, W. Petry, in International Meeting on Research Reactor Fuel Management (RRFM), Berlin, Germany, 2016

17. G. Zaz, Y. Calzavara, E. Le Clézio, G. Despaux, Adaptation of a high-frequency ultrasonic transducer to the measurement of water tempreature in a nuclear reactor, Phys. Procedia 70, 195 (2015)

18. G. Zaz, A. Dekkious, P. Meignen, Y. Calzavara, E. Le Clézio, G. Despaux, High frequency transducer dedicated to the high-resolution in-situ measurement of the distance between two nuclear fuel plates, Phys. Procedia 70, 191 (2015)

19. Nuclear Regulatory Commission, Washington, DC (USA) Office of Nuclear Reactor Regulation, Safety evaluation report related to the evaluation of low-enriched uranium silicide-aluminum dispersion fuel for use in non-power reactors (NUREG-1313), United States, 1988

20. R. Duperray, L. Roux, in International Meeting on Research Reactor Fuel Management (RRFM), Swemieh, Jordan, 2019

21. M. Boyard, in International Meeting on Research Reactor Fuel Management (RRFM), Swemieh, Jordan, 2019

22. J. Koubbi, M. Boyard, F. Huet, V. Romanello, A. Dambrosio, M. Hrehor, in International Meeting on Research Reactor Fuel Management (RRFM), Swemieh, Jordan, 2019

23. B. Stepnik, J. Allenou, C. Rontard, C. Schwartz, C. Steyer, B. Baumeister, W. Petry, S. Van den Berghe, A. Leenaers, S. Valance, H. Palancher, E. Hervieu, Y. Calzavara, H. Guyon, in International Meeting on Research Reactor Fuel Management (RRFM), Swemieh, Jordan, 2019

Cite this article as: Stéphane Valance, Bruno Baumeister, Winfried Petry, Jan Höglund, Innovative and safe supply of fuels for reactors, EPJ Nuclear Sci. Technol. 6, 40 (2020) 